\title{
ELABORATION OF MAIN METHODS OF USING COLORISTICS AT CREATING THE ECOLOGICAL INTERIOR SPACE INCLUDING ARTWORKS
}

\author{
Oksana Pilipchuk \\ Department «Drawing and Painting» \\ Kyiv National University of Construction and Architecture \\ 2 Preobrazhensjka str., Kyiv, Ukraine, 03037 \\ artist-30-03@yandex.ua \\ Yurii Kolomiiets \\ Department «Drawing and Painting» \\ Kyiv National University of Construction and Architecture \\ 2 Preobrazhensjka str., Kyiv, Ukraine, 03037 \\ artist-30-03@yandex.ua
}

\begin{abstract}
The paper analyses harmonization conditions of a color solution, obtained as a result of combining colors that create the united coloristic space-color field, able to create the esthetically full-value tonality of an accommodation. There have been elaborated main methods of using coloristics at achieving the ecological space and harmony of a color solution, including artworks.

There has been proved a necessity to organize the subject-spatial environment by laws and means of coloristics at realizing ecological problems and esthetically improving the environment of human life activity. It has been noted, that under conditions of sustainable development of the environment, at searching for innovative approaches to methods of ecologization of an interior of different destinations, there is a necessity of special scientific methods, theoretical and practical steps that would be instruments for modern artists and designers.

There have been defined a series of unalienable factors of the color environment, connected with each other that can be instruments of ecologization of an accommodation by means of coloristics.

There has been offered a series of functional possibilities of artworks, placed in the coloristics of the spatial environment for creating optimally comfort conditions for human being in it. Using the conducted analysis and given examples, realized by the author of the paper, there are presented main methods that can be the same instrument in the work of an artist-designer that allows him/her to solve the problem of improving ecologization of the interior environment with more professionalism, and also the creative task in placing artworks in the coloristic space of an interior.
\end{abstract}

Keywords: ecology, coloristics, interior space, artworks.

\section{Introduction}

Modern requirements of the interior space are, in the first turn, in functionality, ergonomics and comfort. At that design original spatial-figurative conceptions are connected with new tendencies and stylistic directions, and most of all with the development of innovative technologies. This all naturally results in solving problems of expediency and correspondence of using different types of imitative means in the interior space. At that harmonization of a color solution - it is not only one of means of the esthetical influence of the external environment, able to be a source of beauty, subjecting to laws of "beauty" in design, admiration, inspiration, excitation, but also can be an effective technique, able to create the ecological space.

Today there are many fundamental works about the problem of color and coloristics in the architectural space, mutual connection between coloristics and form, total illumination, light and color reflexes, for example: Zeugner G. [1], Déribéré M. [2], and other revealed form-creating and coloristic properties of a material in the environment, and also problems of using materials in imitative art. A famous researcher of color problems Auer H. [3] determined the role of light in the spatial environment in perception of diverse surfaces that exist in an interior as one of main designing means. Scientists Meerwein G. and Rodeck B. [4] proved the dependence of a material texture on form perception and offered the notion "brightness signal", considering this phenomenon crucial 
in the visual influence of the illumination system. Famous scientists Bribba C. A., Greated C., Collins M. N. [5] consider coloristics as a means of creating balance and harmony in the interior environment. The special attention must be paid to the paper of Dutch researchers Van Assen J. J. R., Wijntjes, M., Pont S. [6, 7] about the influence of illumination of the spatial structure on luster perception in artworks in the environment. It must be also noted, that for today there is a lack of literature and scientific-methodical maintenance in practical use as to ecologization of possibilities of coloristics of the interior space. Modern literature on color, colorostics of an interior and artwork mainly orients on the experience of past years. So, there is a need in finding new methods and innovative approaches for purposeful designing at creating ecology of the interior space by means of coloristic possibilities.

The aim of the research is to elaborate main methods of using coloristics at creating the ecological interior space including artworks.

\section{Materials and Methods}

Color plays an important role for human orientation in the space, translation of a functional content, emotional-esthetic effect, formation of favorable psychological comfort [8]. The coloristic solution of the interior space, obtained as a result of colors combination, is able to form the esthetically full-value tonality of an accommodation - harmony of the artificial environment that doesn't cause irritation, is able to result in a feeling of comfort and cosiness, synchronously solving a task of the stimulating effect of color [9]. At realizing these tasks, one in the first turn needs knowledge about color properties - scientific explication of the nature of color, main laws of coloristic perception and perception mechanism of color combinations, that connect different sciences in the united whole and are mutually adding: optic ones (visual perception of their characteristics), physical (distribution of a light flow, power and length of radiation waves), physiological, ecological, psychological and emotional $[10,11]$.

It is also necessary to take into account a series of external factors - exterior, where an influence may be caused by the geographic location (Southern or Northern regions), orientation of an accommodation by the world sides, texture of surrounding surfaces, and also a certain amount of light rays with their brightness force and reflecting capacity [12]. One of main factors that influences formation of the human color vision is orientation of an accommodation by the world sides that includes a microclimate of accommodations that depends on atmospheric conditions (naturalclimatic peculiarities, annual light regime, wind regime, cloudiness, precipitation amount, pollution, dustiness, noise, humidity, smells and so on), a world side, where an accommodation is located from, (illumination-orientation, intensity of solar radiation, spectral composition of solar radiation, temperature regime) and also a type of illumination - a character of a natural and artificial source of illumination, illumination degree and so on $[13,14]$.

So, the balanced color harmony in an accommodation, based on artistic methods, coloristic means and ecological principles, may be achieved only taking into account all elements of the interior and also adjacent factors. Finally, a color in the interior must cause an optimal psychological condition of a human, experience of positive emotions.

\section{Experimental procedures. Possibilities of coloristics of the ecological interior space includ- ing artworks}

Together with an emotional and figurative influence, artworks may have a significative meaning in the interior, and also may play a functional role in several situations. For example, it is known, that a certain color gamut of artworks may favor an increase of the psychological feeling of warmth or cold, a plotline may cause the same effect [15].

Artworks with a certain form, conditioned by a composition idea, depending on a light source, coloristic surround and also their texture and volume, have different areas and so, color intensity degree, own and falling shade [6]. A reflecting capacity of color is characterized in percents. For example, $100 \%$ means that whole light, falling on a surface, is reflected [14]. A light bundle bears in itself waves of all seven colors of the rainbow. Falling on an object, only waves of the same color with an object one are reflected, other ones are absorbed by the object. Objects 
that reflect light, falling on them, change the local coloration of neighbor objects by their reflected color $[2,5]$. Neighbor objects also influence adjacent ones by their reflected color. This mutual influence of objects causes new color combinations, impression of volume and space intensify, objects gain the coloristic interconnection with the whole external environment. Thus, all colors of subjects, perceived by us, are determined also by reflected rays - reflexes, sent by subjects to each other [12]. It may be also said, that a reflex it is an influence of the external environment on an object.

Influence forces of a light flow in the interior space in the first turn affect its color solution. At that the interior consists of color combinations, where a proportion of their use is important. An oversaturation, disproportion can cause color tiredness, and a lack - color hunger [5]. According to coloristic laws, it is best to look at an additional color for taking color tiredness away [14]. The same effect can be caused also by color reflexes. A reflex mainly depends on a color of subjects and color mixture of light rays, so not only a subject is influenced by the external environment, but a subject itself can influence a color of the surround.

At designing an interior, one must remember that a coloristic solution of the whole space includes not only a color of architectural-constructive elements, but also a coloristic interconnection of the functional equipment and included artistic-decorative elements, and also light flows, inseparably connected with the whole environment and is the mutually connected totality of color and light reflexes that affect each other, creating the unity of a color tone, rich interconnected color harmony.

\section{Results}

As a result of the conducted analysis, there have been determined the main conditions in achieving the ecological space, depending on the series of factors:

1) Illumination type - day natural illumination (morning, day, evening, night illumination, dusk) and artificial (directed illumination source, dispersed, reflected); diverse devices of artificial illumination (different by their spectral composition - color light); type of an illumination source: directed (gives the most illuminated form surface with abrupt and deep falling shades); dispersed (creates non-distinct outlines of a form without shades or with hardy perceived ones, that takes place due to the change of the spatial distribution of light intensity); reflected or reverberated (without shades, so the form of subjects is hardly perceived). At that we must take into account the influence of the total force of obscured surfaces (shades) in the general structure of the interior environment, able to change a composition of a coloristic solution [3, 7]. Each color has a certain force of light absorption and reflection, depending on its spectral composition and illumination force. If a color belongs to a certain texture of a material, its reflection or brightness force changes, so perception of the form, carrier of this color, changes too (Fig. 1-3).

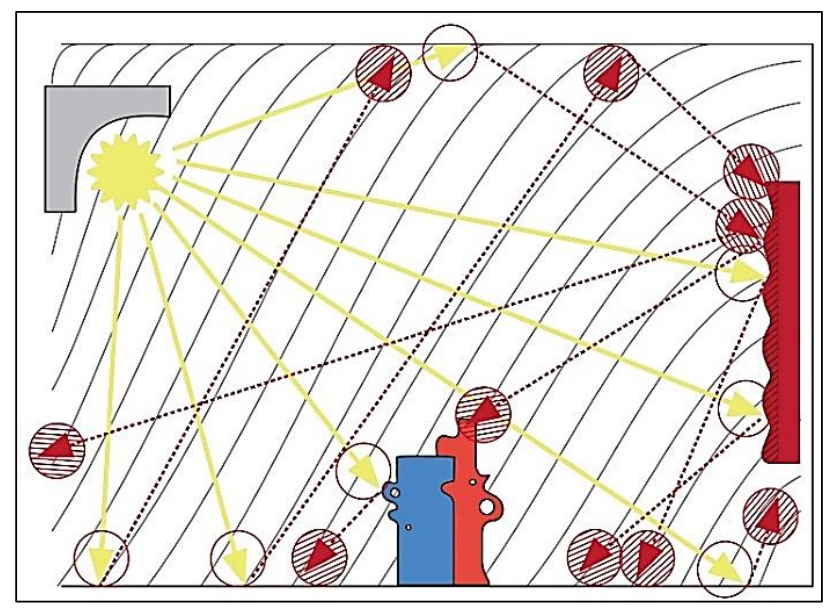

Fig. 1. Scheme of reflexes' reverberation in the interior environment: $\mid$ - texture of the material of the artwork; $r$ - directed illumination source; - reflected light ray; - light ray; - visible space; 1 - equipment 


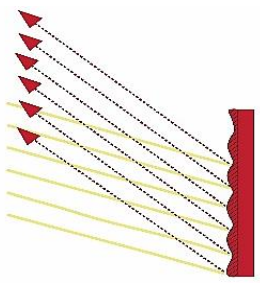

$a$

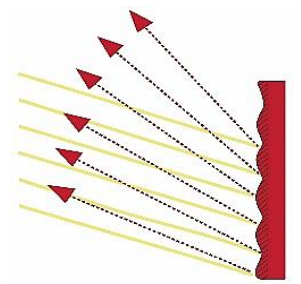

$b$

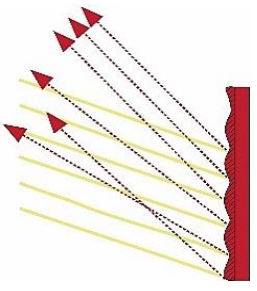

$c$

Fig. 2. Reverberation type of color and light reflexes depending on type of artworks' texture: $a$ - mat texture; $b$ - semi-mat texture; $c$-glossy texture

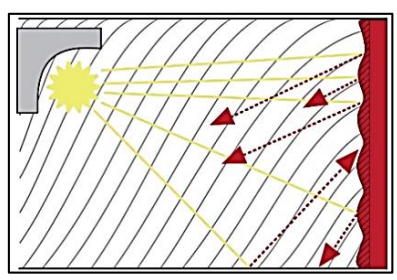

$a$

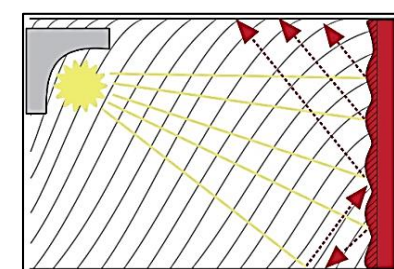

$b$

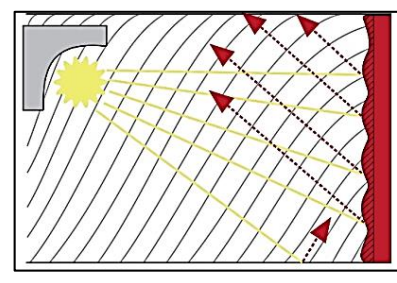

$c$

Fig. 3. Brightness force and number of color and light reflexes, depending on texture type of artworks on the example of the directed light source: $a$ - at mat texture; $b$-semi-mat texture; $c-$ glossy texture

2) Artwork texture. A mat, semi-mat or glossy degrees of the external volume, relief of an artwork also have the ability to increase or decrease the total illumination of an accommodation. The spectral composition of light actively influences perception of the total coloristics in the interior and is also able to change color combinations of surfaces in the interior space differently. Such conditionality of colors depends on falling angle of a light flow and also on distance between the color surface and light source. These parameters are form-creating factors, because they illusively approach or remote surfaces of artworks and space of the interior, underlining its deep or frontal, plane or salient character.

3) Material type and specificity. The space of the interior environment and inclusion of artworks in it contains a large number of materials, different by their properties and structure, using the diversity of technical methods of materials in whole, combinations of traditional and innovative approaches due to the scientific progress in nanochemistry, nanotechnological approaches. The scientific invention of new technological materials opened wide possibilities in different branches of human activity, touching also all spheres of modern imitative art. The utilitarian technological character of new materials is successfully combined with artistic-figurative and decorative property. Modern requirements to materials at solving coloristics, cover type, technology of processing and composition is safety that includes ecological, innovative, economic, functional character and expedience together with a creative origin [12].

Just the same way new technologies and created new requirements to specificity of different types of imitative art are able to transform and to enrich possibilities of designing the ecological interior. For example, the use of saturation of fluorescent colors (in darkness an image or subject, processed by a self-lighting paint, begins to give energy, accumulated during the light day, or in the process of artificial illumination that can increase the energy efficiency of an accommodation), or thermal-chrome paints that change their color, or nanotechnologies that influenced the rise of the new direction in imitative art - "Nano-art".

4) Total coloristics of the environment. Color it is a process of an impression that appears in the sight organ, when light affects it, a light property causes certain visual experiences in correspondence to the spectral composition of reflected or emitted radiations. Light of different waves' length provokes different color experiences. A coloring may be warm or cold, light or dark, relative to the general tonality and saturation. A light degree of polychromy changes with a change of illu- 
mination coloration that is connected with a reflection coefficient [4]. Coloristic warmth-coldness and total light-tonality degree in the interior environment must work in the first turn for realizing a general compositional idea. At that one must remember that reflective reverberation of neighbor colors can completely change the warmth-coldness and light-tonality of the total coloristics. In the interior environment a color tone, light degree, saturation and texture of the form surface are also one of main means in creation of total illumination of an accommodation. That is why the successful use of color combinations, taking into account physical bases of a color is very effective in the ecology of the interior space.

It must be also remembered that a proportion of used colors is important in a coloristic composition. An oversaturation, disproportion can cause color tiredness, and a lack - color hunger. According to coloristic laws, it is best to look at an additional color for taking color tiredness away. Dissonances are inadmissible in a harmonic color composition, psychologically negative colors that provoke a feeling of disgust are impossible.

\section{Discussion}

As a result of the conducted study, there have been determined possibilities of coloristics in creation of the ecological interior space including artworks. Namely: at designing the ecological interior, it must be remembered that a coloristic solution of the whole space includes not only the total polychromy of architectural-constructive elements, light flows, but also the coloristic interconnection of the functional equipment that is a widely-known fact, proved by famous researchers Sorel K. [13] Meerwein G., Rodeck B. [4], but at designing the ecological interior, one must take into account artworks, included in the space. The authors of the paper have revealed, that methods of artworks perception, taking into account the influence of general factors of the space, where they are located, offered by famous scientists Van Assen J. J. R., Wijntjes M., Koenderink J. J., van Doorn A., M. Pont S. [6, 7] can be also instruments of increasing the ecology of the space, for example, by illumination means, character of the form structure and coloristics. At that it is explained, that satisfaction of human psychophysiologic needs, reaction to a color irritative or calming, is connected with a color characteristic, with the notion of tone, brightness, saturation, and also warmth-coldness - color associations that most often depend on subjective characteristics - color advantages, comfort, necessity, expedience of color combinations and general tonality, esthetical influence that is connected with a feeling of beauty and visual ecology of the total space.

\section{Conclusions}

So, we can make a conclusion that under conditions of sustainable development of the environment, at searching for innovative approaches to methods of ecologization of an interior of different destinations, there is a necessity of special scientific methods, theoretical and practical steps that would be instruments for modern artists and designers.

1. Knowledge of laws and possibilities of coloristics, expedience of a color solution are especially important at designing the ecological environmental surround of a human.

2. At that the influence of color and light reflexes of the environment plays an important role in formation of the total interior space. At designing an interior, one must remember that a coloristic solution of the whole space includes not only a color of architectural-constructive elements, but also a coloristic interconnection of the functional equipment and included artistic-decorative elements, and also light flows, inseparably connected with the whole environment.

3. An artist-designer in the work already at the initial creative compositional stage must use means that favor creation of the rational space that results in ecology increase together with esthetical factors of the coloristics influence in the interior.

4. Consistently observing all conditions, one must achieve the necessary emotional impression (visual ecology) from the realized space, to gain the most expressiveness and unity of perception in realization of a creative idea, to create a certain image and correspondent atmosphere that finally may result in the comfort psychological and emotional condition of a human within it. 


\section{References}

[1] Zeugner, G. (1963). Farbenlehre für Maler. Berlin: VEB Verlag für Bauwesen, 168.

[2] Deribere, M. (1959). La couleur dans ls activités humaines. Paris: Dunod, 192.

[3] Auer, H. (1983). Lampen - künstliche lichtquel·len tür jeden denkbaren zweck. FARBE + DESIGN. Gaildorf: GmbH \& Co KG, 25/26, 18-25.

[4] Meerwein, G., Rodeck, B. (2007). Farbe - Kommunikation. Basel - Boston - Berlin: Raum Birkhauser Verlag AG, 152.

[5] Bribba, C. A., Greated, C., Collins, M. N. (2011). Colour in art. Boston: Witpress, 145.

[6] Van Assen, J. J. R., Wijntjes, M. W. A., Pont, S. C. (2016). Highlight shapes and perception of gloss for real and photographed objects. Journal of Vision, 16 (6), 6. doi: http://doi.org/10.1167/16.6.6

[7] Van Doorn, A., Koenderink, J. J., Pont, S. (2012). Shading, a View from the Inside. Seeing and Perceiving, 25 (3-4), 303-338. doi: http://doi.org/10.1163/187847511x590923

[8] Frieling, H. (1979). Farbe im Raum. Angewandte Farbenpsychologie. München: Callwey Verlag, 170 .

[9] Pile, J. F. (1995). Intererior Design. Second Edition. New York: Harry N. Abrams. Inc, 584.

[10] Devan, D. S., Logan, K.-C., Kness, D.-M. (1980). Introduction to interior design. New York: Macmillan publishing Co., Inc, 561.

[11] Lewitzky, H. (1966). Mene Wohnung. Berlin: Veb Verlag für bauwesen, 184.

[12] Kalynycheva, M. M. (2012). Tekhnycheskaia estetyka i dyzain. Moscow: Akademycheskyi proekt: Kultura, 356 .

[13] Sorel, K. (2007). Prostranstvo i svet. Moscow: Kladez-Buks, 139.

[14] Fleury, P. (1930). Couleurs et colorimetrie. Paris: Librairie scientifique Hermann et cie, 33.

[15] Itten, I. (1981). Kunst der Farbe. Rawensburg, 236. 